\title{
Psychology of Digital Games and Its Effects to Its Users
}

\author{
L. K. Pulasthi Dhananjaya Gunawardhana1, Sellappan Palaniappan² \\ ${ }^{1}$ Department of IT, School of Science and Engineering, Malaysia University of Science and Technology (MUST), \\ Kelana Jaya, Malaysia \\ ${ }^{2}$ Department of Information Technology and Telecommunication, School of Science and Engineering, Malaysia \\ University of Science and Technology (MUST), Kelana Jaya, Malaysia \\ Email: Ikpdg87@gmail.com
}

Received 15 August 2015; accepted 13 September 2015; published 16 September 2015

Copyright (C) 2015 by authors and Scientific Research Publishing Inc.

This work is licensed under the Creative Commons Attribution International License (CC BY).

http://creativecommons.org/licenses/by/4.0/

(c) (i) Open Access

\section{Abstract}

In this article, I will discuss the effects of playing digital games. Most of the researchers have found out that the effects by playing digital games are greater than the effects by watching the television or movies. I will be discussing mainly the three scopes which support to argue and allow people to get beyond the typical "good-bad" dichotomous thinking to have a more nuanced understanding of the digital game effect and the insights from developmental, positive, and social psychology combined with other learning mechanisms in playing digital games as well as how far it is possible adopt it to real-world psychosocial benefits scenario will also be examined in this article.

\section{Keywords}

\section{Video Games, Educational Games, Gamification, Child Phycology, Video Games \& Psychology}

\section{Introduction}

Children who were born early $20^{\text {th }}$ century (pre-modern era) used to play with what they were given by the nature. They ran through the streams, climbed trees and played with animals. As a result, they were intelligent and healthy. With the development of technology cities were created which are concrete jungles. The children of this era do not have enough space run around and play outdoor games. So most of them were confined to their houses and spending their free time playing digital games. The digital games were initially introduced in the year 1958 and thereafter development rapidly increased in next few decades.

It is estimated that $80 \%$ of the children aged from 5 to 18 play video games during their leisure time. Digital game is a tool with gaming activities which could contain meaningful educational factors and components which 
can contain educational factors or components. Recent research studies have focused on the potentials of the digital games and exposures children getting from it. The paybacks of the digital games are assumed in the backdrop of children's true motivations to play digital games. Two researchers once said that, the teachers are looking for proper educational games supporting class room activities as an additional supplement. Game Developers, psychologist and educationist try to recognize what is likely to engage a small child in digital games and type of emotional or developmental needs that should address (Salich, Oppl, \& Kristen, 2006). In this article, I am planning to examine and explain how digital games/educational games work and how these games will affect the children who use them.

Educationist and researchers have been recognised the potential of using digital games as an educational tool sometime back. Working on this knowledge, they have started researching on how to apply games into classroom activities in different subjects and modules. Games could be used in many pedagogical aspects such as motivating and inevitably provide the repetition, leave by the user, getting feedback etc. It is easily taught and understood too. In general the problem for all the parties such as, parents, educators, game manufacturers, and researchers are that the differentiating the pomposity is harmful and eventually lose the point. As found in previous researchers carried out in the same topic, there are three key scopes that affect to games players. These scopes are:

1) Content of the Game;

2) Structure of the Game;

3) Game Mechanism.

My next step is to further discuss about these three scopes and how they affect the intended exercise. It is probable that the scopes are networked with each other.

\subsection{Content of the Game}

The content of the games is the key aspect on which the whole exercise is dependent upon. That is what would attract its player to a particular digital game. The content of the games could be a mathematical sum, a puzzle, racing against each other or a shooting scenario. There are many ongoing research on finding out the effect from digital games on children's psychology with insufficient on gathered over a period of time. A researcher named Anderson once mentioned that children who involve with violent digital games, showed a high level of aggressive cognition, aggressive emotions and aggressive behaviours (Anderson, 2004). Another group of researchers have observed that, if games content comprise prosaically activities which can assist to grow nonviolent gaming experience, then it would be predicted that prosaically behaviour in both the short term and the long term basis according to the result of surveys (Gentile, Anderson, Yukawa, Saleem, Lim, \& Shibuya, 2009). Most of the educational digital games are teaching either mathematical sums or reading or proper pronunciations. At the same time some digital games have been designed for health, management, training pilots, etc. According to the previous research reports, most of the research related to these aspects has been very successful as these games are very good at teaching the intended content. Generally it is clear that children learn through game content, which affect their future behaviours.

\subsection{Structure of the Game}

In a proper digital game, the game should display the required information for its player to know how it should play. This process has to be structured properly and accurately to pass meaningful information. If each part of the game does not connect properly like a story or film, the player would not have sufficient interest to continue to play that digital game. As a result, the structure of the digital game should be more descriptive and enlighten to its player. As for the previous research reports, the attraction of a digital game depends on its visual effects, sounds, etc. This can be seen in most of the action games, especially in games with violent features. These visual effects can increase the attention to its targeted audiences as well as its players. In an action game, players need scan their screen constantly as the enemy can pop out from nowhere. The player should be alert enough to notice even minor changes to react promptly. In digital games player has to navigate by themselves to play the game. Either the virtual world is 3D or 2Dthey have to walk or drive on the platform to achieve the given task. A group of researcher have mentioned in one of their report that due to the above aspect digital games can improve navigation skills as well as place of learning and path finding skills of its player (Canovas, Espinola, Iribarne, \& Cimadevilla, 2008). That is not all, as the player needs to sustain the awareness and orientation of the digital game 
and its given objectives, it is too obvious that digital games can improve mental rotation skills. In theory, when the teachers are trying to teach using various theories, its logical application can enhance student or the game player learning skills. Thus, as the screen representations become more realistic, all other effects are too raised.

\subsection{Game Mechanism}

There are four vital parts in game mechanism. They are:

Points - Point are used as key currency of the game. To earn points, player has to work hard and try achieving the given task. As the nature of human being is collecting wealth and valuable resource, the point is a great method to illustrating players' progress and capacity compared to other players. The point system makes the player highly motivated and it is highly effective at the same time. In this way, the teachers also can identify the weak student and find out their weak area.

The reward-Reward is another method that to encouraging player to play the game and spend more time with the game. Once the player complete the given task or the particular stage successfully player will be rewarded. These rewards must be non-monetary and this doesn't include for earning points. It is more like a teacher or the school by way of gift for high performance in an examination.

Badges - This method is to highlight the player's competencies. Other players will recognise the talent of particular players in that particular. In digital games the players are easily identified by the number of badges they earn. Badges symbolise player's profile, achievement records, and they are responsible for highlighted the challenges they have faced in playing a particular game.

Leader Boards - Leader Boards are used to shows the progress made by a player in a particular game. The collection of points and badges are notified in Leader Boards. Having collected points, badges, etc. and displaying them in a leader board, the player can improve his/her ranks and a way of recognition among other players. Leader board also helps a player in a lower rank to improve ranking by compete players' ranking with others. Leader board is therefore the element that drives the player's fulfilment for their target rewards and motivates them to finish the game successfully.

\section{Psychology of the Video Games}

\subsection{Characteristics}

Digital games research continue to be enriched by new inputs and the main objective of digital games has shifted a great deal.Development of technology has also helped to changing of styles of digital games and continue to change in future as well. The rules of digital games can be changed according to market strategies. Previous research done on digital games show the effects of the digital games and strength of digital games, but we still require more data and figures to comprehend the potential of digital games and the level of dedication required to make it a universal package. If games can change mind-set of a player, it could be used for a good cause like education.

When we look at previous research done about the digital games, it is difficult to interpret them and measure them in one yardstick. Since these researchers have been carried out to measure to conclude their own interpretation and assumptions rather than measuring actual and industrial differences of different games players. However some researchers have shown us there exist dissimilarities in reaction to the video games (Guimetti \& Markey, 2007). As the Slater and his group of researchers have found out in their work "Downward Spiral Model", the connection media may emphasise are the aggressive behaviours, feelings, and thought of the game player (Slater, Henry, Swaim, \& Anderson, 2003). In 2009 another two researchers argued that, if children addicted to digital video games and elevated levels of psychoticism, it can be disturb the child psychology (Markey, \& Sherer, 2009). At the same time other researchers have stated that desire to play different types of games may play a part in restraining the bad effect. These researchers have also suggested that aggression, neuroticism and anxiety made through by playing action games may influence of digital gaming as well.

Though most of the researchers say that the video games give negative behaviours there are plus points in the game as well. In order to assess the violent aspect and violent behaviours, when compared with game contents some researchers thought that, the answer lies with violent and non-violent game contents. Finally they have concluded that, not the content alone but the time spent on games also play a role in fashioning the behaviour of a player. At the same time the specific time of the day in which a player involves killing or shooting games is 
also has an impact of their behaviours. As result the researchers have found out the time spent on playing gems have an impact on their school performances and also violent gaming content promote violent behaviours. These researchers have argued that, the students will be more interested in their school work when they are allowed to play more educational games. This will enhance their educational performance as well. In 1998 a group of researchers have stated that the students who used to play digital games involving non-educational games usually performed poorly in their school work as against those who used their use computers for educational purposes (Lieberman, Chaffee, \& Roberts, 1988).

\subsection{Psychological Effects on Digital Games}

When we are researching the effects of the digital games, question which is popped up to asked the extent of digital gaming experience which can effect on thinking abilities. Gentile highlighted the four proportions that describe and discuss the time spent by children playing digital games as a habit. These proportions are:

Amount: This leads to considerations about digital game addiction.

Content: This deal with the effects of the messages conveyed by the digital games as a media. Previous research about digital games causes to have observed that they effect the behaviours attitudes and skills of the game player.

Form: This refers to a grow knowledge. Practicality is an issue which is enclosed in this aspect.

Mechanics: This refers to both input-output devices use for gaming. Involvement with game would be a different one than depending on the interface. But the results which effects to learning could different.

Whatever the proportionsthe most credible outcome could be found out through a research. In such a scenario we need two groups of children. One group is the children who inexperienced as a gamers and others are casually assigned the trained children to play the digital game for the same period of time. When compared those who are experienced in gaming shows accuracy on their attention, enhanced thinking and logical abilities. The previous research papers have also demonstrated that talents for certain educational subjects can be levelled up when practicing with the digital games in quite short period. All the same time these types of skills could be applied outside the gaming context as well. Previous research reports in these areas have highlighted that the cognitive advantages of the gaming could be measurable and the changes and those changes affected in neural processing can be effective. A group of researchers reported in a magazine named "Nature Reviews Neuroscience" that; "the digital games are controlled training regimens delivered in highly motivating behavioural contexts... because behavioural changes arise from brain changes, it is also no surprise that performance improvements are paralleled by enduring physical and functional neurological remodelling” (Bavelier, Green, Han, Renshaw, Merzenich, \& Gentile, 2011).

It is impossible to select a proper and a controllable situation where all varieties of a digital games retained and cognitive challenges are controlled. Problem solving skill could be seen in each and every type of digital games genres. Instead of learning by going through the instruction, most of the children like to learn things by activities doing by themselves. Recent research articles show that by playing strategic games the player can improve their skill levels in problem solving, better academic score, etc. Digital games are associated with good and creative cognitive skills. As to recent research reports, it has been confirmed that children who play digital games have increased creativity children who use other forms of technology such as like internet, mobile phones etc, do not have the same kind of creativity. Most of the digital games are made to increase the cognitive functions of users, while some other digital games are generalize the real-world contexts. Contemporary researches observe that negative impact of the digital games must be balanced and cognitive benefits from digital games should build these negative aspects. Digital games always try to build positive feedbacks on users' motivation. This will help to increase user's ability to make difficult jobs easier by either through practice or logical thinking. Digital games can motivate children when they feel nervous or not sure about their capacities. If the children or the user's using of digital game use in a correct way, it is very effective and could control user behaviour at the same time.

Positive Effects-According to the previous research articles, impact of the digital games vary in terms of different levels focussed on different learning aspects. Digital games are usually powerful learning tools as they are active, and able to do problem-based solving through different type of puzzles and techniques. Digital games have the option of self-assessment, and social learning environments, which allow vendors to learning from different perspectives. Digital games could also be used to develop social skills in people with disabilities. Digital 
games open the door for children to explore the world and real world society in many ways and also it is a possible avenue of teaching physical education to children in schools.

Negative Effects-The previous research done about digital games shows not only the positive aspect, but negative aspect as well. Such research has pointed out that that playing digital game continuously causes to physical pain such as like; Nintendo thumb and epileptic seizures, joint, muscle, and skin problems. Some researchers have argued that, playing digital game can have an effect on school work as the students who are addicted to digital games usually involve themselves with the game for long period of time. All the same when children play violent digital games they tend to develop violent behavioural patterns. It has been revealed that $90 \%$ of the digital games available in current market are contains violent elements and activities. A researcher who has explored the concept of hostility and found out aggressive behaviours are more evident in students just after playing of violent digital games.

\subsection{Motivational Facts}

To build better video game, games developers have to explore the motivational facts of the children's. We can see that children who play games are motivated to play their favourite games and can noticed that they turn into provoked while they play particular game. This may affect to concentration for the game, and it will reflective effects on learning as well. Digital games have got couple of features which motivates its players to involve with the game and tight it up inside the game. The difficulty of the certain level will make the children practise their skills to win the level and move to higher levels and eventually they can be the experts. When we take children their learning abilities and capacities are not in a same level. So both game developers and teacher have identify that and develop the game for suitably. By playing difficult levels of a game will helps children's gains experience and they will get ready for the next difficult level.

A group of researchers have explored the connection psychological factors for digital games. They have found through their research that the games which gives freedom to its players, will accomplish their given target quickly and actively. Characteristics of a successful game are; setting goals, meeting challenges, planning strategies, and essentially controlling their own actions. And also they said violence activities did not associate with more enjoyment once the need for independence and competence was taken into account. Developing a game means to have the same basic characteristics as violent digital games, but without applying violent factors such as fighting, killing and shooting, could attract new audiences (Przybylski, Rigby, \& Ryan, 2010).

Not that all another research group found that development of a child psychological intelligence and abilities, beliefs that inspire the certain motivational factors and it will affect to their achievements as well. Children who are admired for their qualities rather than their efforts, develop an entity for their tidings, which maintains that intelligence is an innate quality, something this quality will fixed and cannot be improved. Nonetheless, children who are admired for their effort will produce an incremental theory of intelligence. Only they believe intelligence is flexible, something that can be gained through effort and time. So they suggest that digital games ideal for training purposes to obtaining an incremental theory of intelligence, as digital games deliver abrupt feedback for its players (Dweck, \& Molden, 2005).

In 2001 researcher named Fredrcikson said that significance experiencing positive motivations on a daily basis has been expanded. She reveals that experiencing motivational facts could help to increase positive behaviours and observes possible and motivate and build social relationships which support for purse their goals. And also she said, that positive motivational factors could help to undo the damaging and de-motivating factors. Positive motivations are key factors of wellbeing, crucial not only as end states, but as sources of inspiration and connectivity (Fredrickson, 2001).

\section{Game as a Learning Mechanism}

The most noticeable difficulty in using digital games as a tool to investigate its learning mechanism is, when the gaming background is really complicated. Generally game players are involved in multiple activities. The demands of the digital game vary from time to time and situation to another. Developing the game in an appropriate environment and code its behaviour and to gain an assessment of which cognitive functions are likely to have been activated is a challenging task. For these kind of problem it is hard to assess or evaluate the link between game action and brain functions, and to see the vital aspects of training which may have brought about the development. A researcher once mentioned that conventional training experiments is isolation along with ra- 
tional functions could help to learning fast. This can be result of less effective retention for the given tasks (Burgess, 2008).

A group of researchers once mentioned that positive changes can be effected by duplicating various tasks (Karni \& Sagi, 1991). Development of certain areas for the task of training and generalization of training are two distinct conditions of the initial learning stage which we rarely see. But it is motivating to see that accomplished for transfer used in digital games and the skills of trained players were seems to be long lasting. In digital games some tasks required working with good memory to make it a challenging one. Some other tasks may require complex problem-solving skills, though another set of task are performed quickly after without aware intervention. Some tasks needs basic, such as fundamental capabilities like spatial selective attention or spatial working memory.

By playing digital games can improve the spatial attention and concurrently increase the performance of mental rotation task. The mental rotation certainly depends on perceptual and intellectual processes mentioned above and all same time beyond the spatial attention. Some of the extra functions could also be developed by playing the digital game, but that is not all. Sometimes the digital games players is free to use his skills and this is like real world navigation. Player's brain will fit into dynamically paradigm which given him the spatial illustration of the immediate environment. There are chances of developing new spatial illustrations in digital game. So the setting and the positioning characters could be change regularly. Some of the skills could also be developed during the erection of the spatial illustrations. This may easily transferred to tasks such as mental rotation. On the other hand, it is likely that mental rotation involved with capabilities that receive no benefit by playing digital games. Therefore, there may be restrictions that may be imposed and complex spatial tasks after training with action games.

Previous research studies related to digital game have examined comparatively complex spatial skills such as like mental rotation, embedded figures, or mental paper folding. Even though they not complex as compared to real world experimentation like, learning geometry or designing buildings, tasks like these could be numerous. Generally, the selection of game and principle task will set the boundaries in spite of whatever the accomplished in a training study. When the digital game is used for the purpose of training, it does not necessarily improve basic spatial skills, but it will transfer the learning aspects, and whatever increase to make it possible to effect the developments of the specific task. Nonetheless all the digital games do not improve the fundamentals. But digital games can help recover the spatial skills such as the ability to rotate objects mentally. Yet when compared with training, it is difficult to find any other studies using dynamic puzzles as a digital games. On the other hand, playing action games causes the simplification of the task and such learning has long lasting effects.

A couple of researchers' have mentioned that reversing the hierarchy theory of Ahissar and colleagues' significance's to explain, how processing of the information continues. First of all, feed forward the system transfers information from lower level to higher levels of the cortex (Ahissar \& Hochstein, 2004). The judgement of the structures begins at high cortical levels of using this feed-forward information. Nevertheless, it is required to get regressive to lower level if the judgement cannot be filled with more detail. Therefore, initial processing involves with certain features only, and it will help to develop the physical capabilities after training is expected to result in from top-down directional processes where lower cortical layers are taken once or more when necessary. Trained game players make quick judgments than those without training. Although the beginners need additional information from lower level before they arrive at a judgment. A beginner becomes an expert when the processes of top-down variation have been combined with the feed-forward processing. Connection between top and bottom deliberate an enduring advantage. With the excellence of transferring the learning is expected to be given a specific framework.

\section{Conclusion}

New technology is conversing in the modern world day by day. We see both good and bad side in the present scenario of advancement and use of technology. This applies to digital games as well. Anyhow we can conclude that digital games can be beneficial in many ways if we use it in a proper manner. The digital games in today, few years back and for developing in the future are also unique forms of gaming. Digital game in present status is an evolution from the past and it keeps on progressing into the further with new development. The fact that the digital game is effective in many ways and allows us to scope which allow a way out of dichotomous thinking has now been identified. The characteristics of the digital games show us why children attracting to play 
games, its connection learning and why they consider the key factors of digital games are understanding the effect of excessive playing. Researchers have debated the use of psychological operations which explains the effects of digital game play including the changes in cognition. On the other hand, the arbitrators of the effects could contain developmental stages of player's, cultural elements, and key constituents such as luck and a person's motivation for acting. Digital game play has been indicating that it can improve the spatial skills such as mental rotation and spatial visualization.

\section{Acknowledgements}

I would like to take express my gratitude to everyone who supported and guided me especially my Ph.D. research supervisor, Professor Dr P. Sellappan.

\section{References}

Ahissar, M., \& Hochstein, S. (2004). The Reverse Hierarchy Theory of Visual Perceptual Learning. Trends in Cognitive Sciences, 8, 457-464. http://dx.doi.org/10.1016/j.tics.2004.08.011

Anderson, C. A. (2004). An Update on the Effects of Playing Violent Video Games. Journal of Adolescence, 27, 113-122. http://dx.doi.org/10.1016/j.adolescence.2003.10.009

Bavelier, D., Green, C. S., Han, D. H., Renshaw, P. F., Merzenich, M. M., \& Gentile, D. A. (2011). Brains on Video Games. Nature Reviews Neuroscience, 12, 763-768. http://dx.doi.org/10.1038/nrn3135

Burgess, N. (2008). Spatial Cognition and the Brain. Annals of the New York Academy of Sciences, 1124, 77-97. http://dx.doi.org/10.1196/annals.1440.002

Canovas, R., Espinola, M., Iribarne, L., \& Cimadevilla, J. M. (2008). A New Virtual Task to Evaluate Human Place Learning. Behavioural Brain Research, 190, 112-118. http://dx.doi.org/10.1016/j.bbr.2008.02.024

Dweck, C. S., \& Molden, D. C. (2005). Self-Theories: Their Impact on Competence Motivation and Acquisition. Handbook of Competence and Motivation (pp. 122-140). New York, NY: Guilford Press.

Fredrickson, B. L. (2001). The Role of Positive Motivation in Positive Psychology: The Broaden-and-Build Theory of Positive Emotions. American Psychologist, 56, 218-226. http://dx.doi.org/10.1037/0003-066X.56.3.218

Gentile, D. A., Anderson, C. A., Yukawa, S., Saleem, M., K., Lim, M., \& Shibuya, A. (2009). The Effects of Prosocial Video Games on Prosocial Behaviors: International Evidence from Correlational, Longitudinal, and Experimental Studies. Personality and Social Psychology Bulletin, 35, 752-763. http://dx.doi.org/10.1177/0146167209333045

Guimetti, G. W., \& Markey, P. W. (2007). Violent Video Games and Anger as Predictors of Aggression. Journal of Research in Personality, 41, 1234-1243. http://dx.doi.org/10.1016/j.jrp.2007.02.005

Karni, A., \& Sagi, D. (1991). Where Practice Makes Perfect in Texture Discrimination: Evidence for Primary Visual Cortex Plasticity. Proceedings of the National Academy of Sciences of the USA, 88, 4966-4970. http://dx.doi.org/10.1073/pnas.88.11.4966

Lieberman, D. A., Chaffee, S. H., \& Roberts, D. F. (1988). Computers, Mass-Media, and Schooling: Functional Equivalence in Uses of New Media. Social Science Computer Review, 224-241. http://dx.doi.org/10.1177/089443938800600204

Markey, P. M., \& Sherer, K. (2009). An Examination of Psychoticism and Motion Capture Controls as Mode-Rators of the Effects of Violent Video Games. Computers in Human Behavior, 407-411. http://dx.doi.org/10.1016/j.chb.2008.10.001

Przybylski, A. K., Rigby, C. S., \& Ryan, R. M. (2010). A Motivational Model of Video Game Engagement. Review of General Psychology, 14, 154-166. http://dx.doi.org/10.1037/a0019440

Salich, M. Von., Oppl, C., \& Kristen, A. (2006). What Attracts Children? Playing Video Games: Motives, Responses and Consequences (pp. 147-163). Hillsdale, NJ: Erlbaum.

Slater, M. D., Henry, K. L., Swaim, R. C., \& Anderson, L. L. (2003). Violent Media Content and Aggressiveness in Adolescents: A Downward Spiral Model. Communication Research, 713-736. http://dx.doi.org/10.1177/0093650203258281 